\title{
The inhibitory effect of phosphate on the ligase chain reaction used for detecting Chlamydia trachomatis
}

\author{
T Notomi, Y Ikeda, A Okadome, A Nagayama
}

\begin{abstract}
Aims-To examine the detection limit of the ligase chain reaction kit for Chlamydia trachomatis, to study the inhibitory effect of phosphate on the ligase chain reaction, and to clarify the mechanism of inhibition.

Methods-Three reference serovars of $C$ trachomatis-D/UW-3/Cx, F/UW-6/Cx, and $\mathrm{L} 2 / 434 / \mathrm{Bu}$-were used to test the sensitivity of the chlamydia ligase chain reaction. Comparison was made of the inhibition by phosphate before and after DNA amplification. Phosphate in up to $2.4 \mathrm{mM}$ concentration was added to specimens of $C$ trachomatis serovar D (1 to 50 inclusion forming units (IFU)/reaction) before DNA amplification to examine the concentration dependency of phosphate inhibition of the ligase chain reaction.
\end{abstract}

Results-The detection limits were 0.6 IFU/reaction for serovar $D / U W-3 / C x$ and F/UW-6/Cx, and 0.4 IFU/reaction for L2/ 434/Bu. Phosphate inhibited the ligase chain reaction only when it was added before the amplification stage. The specimens containing chlamydia at 1 to 50 IFU/reaction were negative when the concentration of phosphate added at the prethermocycle stage was more than $1.2 \mathrm{mM}$. Conclusions-Ligase chain reaction analysis is a reliable method of diagnosing $C \mathrm{tra}$ chomatis infection because of its high sensitivity. It would be clearly superior to the currently used methods if the problem of inhibitors could be eliminated. The mechanism of inhibition of the ligase chain reaction by phosphate was thought to be blockade of the amplification of the target DNA. The efficacy of the ligase chain reaction could be inhibited by phosphate in the urine, so duplicate dilution analysis of some negative specimens should be useful. (f Clin Pathol 1998;51:306-308)

Keywords: Chlamydia trachomatis; ligase chain reaction; phosphate inhibition

Chlamydia trachomatis, an obligate intracellular bacterium, is the major cause of sexually transmitted disease in well developed countries. In men who are sexually active this organism causes about $50 \%$ of cases of non-gonococcal urethritis. ${ }^{1}$ Asymptomatic infection is characteristic of this pathogen. In women, asymptomatic cervicitis contributes to many sequelae. Furthermore, maternal chlamydial infections have a direct and harmful influence on the fetus and can lead to several diseases in infants. Therefore, rapid, accurate, reliable, non-invasive, and convenient tests to detect $C$ trachomatis are required for clinical screening. A genetic detection kit for $C$ trachomatis-plasmid based ligase chain reaction - has been developed (Abbott Laboratories, Chicago, Illinois, USA). ${ }^{2}$ The specificity of this kit was reported to be better than that achieved by the polymerase chain reaction (PCR) (Amplicor, Roche Diagnostic Systems, Branchburg, New Jersey, USA).

Sensitive and specific identification of $C$ trachomatis in clinical specimens is essential for the effective control of chlamydial infection. However, as the sensitivity increases, so does the possibility of false negative results. One of the reasons for false negatives is the presence of inhibitors in the test sample. In the present study, the sensitivity of ligase chain reaction and the inhibitory effect of phosphate were examined.

\section{Methods}

PREPARATION OF C TRACHOMATIS

Three reference serovars, D/UW-3/Cx, F/UW-6/ $\mathrm{Cx}$, and $\mathrm{L} 2 / 434 / \mathrm{Bu}$, were prepared. All serovars were passaged serially in McCoy cells in 24 well flat bottomed culture plates. ${ }^{3}$ Stocks were suspended in sucrose-phosphate-glutamate (SPG) medium (sucrose $75.0 \mathrm{~g}, \mathrm{KH}_{2} \mathrm{PO}_{4} 0.52 \mathrm{~g}$, $\mathrm{Na}_{2} \mathrm{HPO}_{4} 12 \mathrm{H}_{2} \mathrm{O} 3.07 \mathrm{~g}$, glutamic acid $0.72 \mathrm{~g}$, distilled water $1000 \mathrm{ml}$ ), and divided into $1 \mathrm{ml}$ aliquots, each in a test tube with glass beads, and frozen at $-70^{\circ} \mathrm{C}$ until used. The titre of these stocks was $1.7 \times 10^{5}$ to $8.0 \times 10^{6}$ inclusion forming units (IFU) per $\mathrm{ml}$ in McCoy cells, which were stained with a fluorescein labelled, species specific monoclonal antibody (Syva, Palo Alto, California, USA). All three serovars were employed to investigate the sensitivity of the ligase chain reaction for detection of $C$ trachomatis, and only serovar $\mathrm{D} / \mathrm{UW}-3 / \mathrm{Cx}$ was used to determine the inhibitory effect of phosphate on the ligase chain reaction.

SERIAL DILUTIONS OF C TRACHOMATIS AND PHOSPHATE

Frozen chlamydial stocks were thawed in an ice bath and mixed with a vortex mixer. Stock solutions of each $C$ trachomatis serovar, with prior determination of the IFU value, were diluted to $32 \mathrm{IFU} /$ reaction with ligase chain reaction urine buffer (provided with the ligase chain reaction kit) to eliminate the influence of phosphate in SPG medium, and then serially diluted up to $0.2 \mathrm{IFU} /$ reaction. These samples were analysed by the chlamydia ligase chain reaction for determination of sensitivity. 
In order to study the inhibitory effect of phosphate on the ligase chain reaction, a stock solution of $12 \mathrm{mM}$ phosphate $\left(\mathrm{KH}_{2} \mathrm{PO}_{4} 0.5 \mathrm{~g}\right.$, $\mathrm{Na}_{2} \mathrm{HPO}_{4} 12 \mathrm{H}_{2} \mathrm{O} 2.97 \mathrm{~g}$, distilled water 1000 $\mathrm{ml}$ ) was prepared. Ligase chain reaction urine buffer was used to dilute chlamydia and phosphate. To examine the inhibitory effect of phosphate on the pre- or post-thermocycle stage, the final concentration of the chlamydias was fixed at $50 \mathrm{IFU} /$ reaction. Phosphate was added at up to 1.2 or $6.0 \mathrm{mM}$ concentration to the chlamydial solution before amplification (prethermocycle) or to the amplified specimens (post-thermocycle) just before detection.

To clarify the relation between the concentration of chlamydias and phosphate, the respective concentration of chlamydial solution containing 0.15 to $2.4 \mathrm{mM}$ of phosphate was prepared and divided into $1.0 \mathrm{ml}$ aliquots, each in a $1.5 \mathrm{ml}$ Eppendorf tube, and stored at $-20^{\circ} \mathrm{C}$ until analysed.

\section{DETECTION}

All samples were assayed within two weeks after preparation and analysed according to the manufacturer's instructions. Briefly, frozen samples were thawed at room temperature and mixed with a vortex mixer. The samples were placed in a heat block at 97 to $100^{\circ} \mathrm{C}$ for 15 minutes. For DNA amplification, $100 \mathrm{ml}$ of each sample were added to a microcentrifuge tube containing a predispensed ligase chain reaction mixture. Tubes were inserted into thermocycler (model 480; Perkin-Elmer Norwalk, Connecticut, USA), programmed for 40 cycles. Each cycle contained a denaturation step of $93^{\circ} \mathrm{C}$ for one second and lower temperature steps at $59^{\circ} \mathrm{C}$ for one second and $62^{\circ} \mathrm{C}$ for 90 seconds. An automated microparticle enzyme immunoassay was used to detect amplification products. The analyser system used a microparticle sandwich enzyme immunoassay based on the covalent labelling of the non-ligated termini of all four oligonucleotide probes with one of two different haptens. Only the products containing both haptens thereby generate a detectable signal in the analyser. The amplicons were detected by an alkaline phosphatase labelled conjugate directed against the hapten. The conjugate catalyses the hydrolysis of 4-methylumbelliferyl phosphate to 4-methylumbelliferone.

\section{Results}

The detection limits of the kit were 0.6 IFU/reaction for serovar $\mathrm{D} / \mathrm{UW}-3 / \mathrm{Cx}$ and F/UW-6/Cx, and 0.4 IFU/reaction for L2/434/ Bu. All samples of each serovar with more than

Table 1 Inhibitory effect of phosphate on chlamydia ligase chain reaction before and after DNA amplification

\begin{tabular}{lllcc}
\hline $\begin{array}{l}\text { C trachomatis } D \\
\text { (IFU/reaction) }\end{array}$ & $\begin{array}{l}\text { Phosphate } \\
(\mathrm{mM})\end{array}$ & Additional period & Counts $\mathrm{s}^{-1} \mathrm{~s}^{-1}$ & Result \\
\hline 0 & 0 & & 7.3 & - \\
50 & 0 & Prethermocycle & 2329.0 & + \\
& 1.2 & 23.6 & - \\
& 6.0 & Prethermocycle & 12.3 & - \\
& 1.2 & Post-thermocycle & 2137.3 & + \\
& 6.0 & Post-thermocycle & 2233.8 & + \\
\hline
\end{tabular}

IFU, inclusion forming units; prethermocycle, phosphate added before DNA amplification; post-thermocycle, phosphate added after DNA amplification; +, positive raction; -, negative reaction.
Table 2 Inhibitory effect of phosphate at the prethermocycle stage of the chlamydia ligase chain reaction assay: relation between the serial dilution of phosphate and $C$ trachomatis $D / U W-3 / C x$

\begin{tabular}{lllllll}
\hline Phosphate (mM) & 0 & 0.15 & 0.3 & 0.6 & 1.2 & 2.4 \\
\hline C trachomatis D, & & & & & & \\
IFU/reaction & & & & & & \\
50 & + & + & + & + & - & - \\
10 & + & + & + & + & - & - \\
5 & + & + & + & \pm & - & - \\
1 & + & + & + & - & - & - \\
0 & - & - & - & - & - & - \\
NC & - & - & - & - & - & - \\
\hline
\end{tabular}

IFU, inclusion forming units; NC, negative control.

these IFU values per reaction were positive, and all samples of lower concentrations and the negative control without chlamydias were negative.

For the examination of the inhibitory effect of phosphate on the prethermocycle stage, phosphate was added to the sample of $C$ trachomatis before heating. The ligase chain reaction produced by a sample of 50 IFU of $C$ trachomatis was completely inhibited when it contained 1.2 or $6.0 \mathrm{mM}$ of phosphate. On the other hand, positive results were obtained when phosphate was added after DNA amplification - that is, the post-thermocycle stage - even if the concentration was $6.0 \mathrm{mM}$ (table 1).

The relation between serial dilution of phosphate and $C$ trachomatis on the prethermocycle stage is shown in table 2. As expected, $1.2 \mathrm{mM}$ phosphate inhibited the reaction even in the most concentrated sample (50 IFU/reaction). All samples containing over $1.2 \mathrm{mM}$ of phosphate were completely negative. Around the detection limit of $1 \mathrm{IFU} /$ reaction, $0.6 \mathrm{mM}$ phosphate caused complete inhibition without exception. When phosphate was added at a concentration of $0.6 \mathrm{mM}$ to the samples containing $5 \mathrm{IFU} /$ reaction, the results were variable, either positive or negative.

\section{Discussion}

Miyashita et al reported that the numbers of elementary bodies and $C$ trachomatis inclusions at the detection limit of both ligase chain reaction and PCR were two elementary bodies and one in situ inclusion containing reticulate body, respectively, per assay. ${ }^{5}$ We obtained similar results but found the ligase chain reaction assay a little more sensitive, probably because we used non-purified chlamydial stocks containing both active and inactive elementary bodies and reticulate bodies.

With increased sensitivity, false negative results owing to inhibitors become prominent. Clinically, false negative results by PCR represent $3.6 \%$ to $17.9 \%$ of cervical specimens and $0 \%$ to $12.9 \%$ of male urine specimens, ${ }^{6-12}$ and false negative results from the ligase chain reaction amounted to $0.2 \%$ to $5.5 \%$, including some that may not in fact have been false negatives. ${ }^{13-17}$ Although false negative results can be caused not only by inhibitors but also by infection with a plasmid-free serovar, careless transportation, technical failure, and so on, the major factor in the occurrence of false negative results is the presence of inhibitors. The principle of the ligase chain reaction makes it 
necessary to consider phosphate as a possible inhibitor. Phosphate could inhibit both reaction stages - that is, the amplification of target DNA and the detection by luminescence. In this study, only when phosphate was added before DNA amplification was ligase chain reaction activity completely inhibited. Therefore we think that the mechanism of inhibition is likely to be blockade of amplification of the target plasmid DNA, suppressing ligation during amplification. On the other hand, phosphate had little influence on the luminescence step following the ligase chain reaction: up to $6.0 \mathrm{mM}$ phosphate had no effect on the hydrolysis of 4-methylumbelliferyl phosphate to 4-methylumbelliferone.

The concentration of phosphate is $12.4 \mathrm{mM}$ in SPG medium and usually 60 to $70 \mathrm{mM}$ in the urine of a healthy adult. We found that over $1.2 \mathrm{mM}$ phosphate on its own acted as a strong inhibitor of the ligase chain reaction. Therefore, samples containing phosphate such as SPG medium should not be used in the ligase chain reaction assay, because it only requires target DNA, not chlamydial survival. Dilution of some negative specimens could be useful in the diagnosis of chlamydial infection by ligase chain reaction assay. For example, the samples containing chlamydia at $50 \mathrm{IFU} /$ reaction and $2.4 \mathrm{mM}$ phosphate gave negative results. However, such a sample would be positive if it were diluted fourfold to 50 -fold with ligase chain reaction urine buffer, as shown in table 2 .

As well as phosphate, other unknown inhibitors may be present in clinical samples. Magnesium is an indispensable ion for amplification by PCR and ligase chain reaction; however, it has been reported that a concentration of over $10 \mathrm{mM} \mathrm{MgCl}{ }_{2}$ reduces the efficacy of PCR by $40 \%$ to $50 \% .{ }^{18}$ Furthermore, we have experimental evidence that whole blood, $\mathrm{Fe}$ ion, and $\mathrm{NaClO}$ also have inhibitory effects on the ligase chain reaction (data not shown). In this study, we demonstrated that phosphate is a strong inhibitor of this reaction and that attention should be paid to its presence when testing urine specimens.
We appreciate the financial and material support by Takashi Shibuya, Dainabot Co Ltd, Tokyo, Japan. We thank for Dr Ataru Kuroiwa for his comments on the manuscript.

1 Stamm WE. Diagnosis of Chlamydia trachomatis genitourinary infections. Ann Intern Med 1988;108:710-17.

2 Dille BJ, Butzen CC, Birkenmeyer LG. Amplification of Chlamydia trachomatis DNA by ligase chain reaction. $\mathcal{f}$ Clin Microbiol 1993;31:729-31.

3 Evans RT, Taylor-Robinson D. Comparison of various McCoy cell treatment procedures used for detection of Chlamydia trachomatis. F Clin Microbiol 1979;10:198-201.

4 Nagayama A, Nakao $T$, Taen $H$. In vitro activities of ofloxacin and four other new quinoline-carboxylic acids gainst Chlamydia trachomatis. Antimicrob Agents Chemother 1988;32:1735-7.

5 Miyashita N, Matsumoto A, Niki Y, et al. Evaluation of the sensitivity and specificity of a ligase chain reaction test kit for the detection of Chlamydia trachomatis. F Clin Pathol 1996;49:515-17.

6 Bass CA, Jungkind DL, Silverman NS, et al. Clinical evaluation of a new polymerase chain reaction assay for detection of Chlamydia trachomatis in endocervical specimens. F Clin Microbiol 1993;31:2648-53.

7 Bauwens JE, Clark AM, Loeffelholz MJ, et al. Diagnosis of Chlamydia trachomatis urethritis in men by polymerase chain reaction assay of first-catch urine. $f$ Clin Microbiol 1993;31:3013-16.

8 Jaschek G, Gaydos CA, Welsh LE, et al. Direct detection of Chlamydia trachomatis in urine specimens from symptomatic and asymptomatic men by using a rapid polymerase chain reaction assay. $\mathcal{f}$ Clin Microbiol 1993;31:1209-12.

9 Bauwens JE, Clark AM, Stamm WE. Diagnosis of Chlamydia trachomatis endocervical infections by a commercial polymerase chain reaction assay. $\mathcal{F}$ Clin Microbiol 1993;31: polymer.

10 Kellogg JA, Seiple JW, Klinedinst JL, et al. Improved PCR detection of Chlamydia trachomatis by using an altered detection of Chlamydia trachomatis by using an altered
method of specimen transport and high-quality endocervimethod of specimen transport and high-quality end

11 Wiesenfeld HC, Uhrin M, Dixon BW, et al. Diagnosis of male Chlamydia trachomatis urethritis by polymerase chain reaction. Sex Transm Dis 1994;21:268-71.

12 Pasternack R, Vuorinen P, Kuukankorpi A, et al. Detection of Chlamydia trachomatis infections in women by Amplicor PCR: comparison of diagnostic performance with urine and cervical specimens. $\mathcal{F}$ Clin Microbiol 1996;34:995-8.

13 Chernesky MA, Jang D, Lee H, et al. Diagnosis of Chlamydia trachomatis infections in men and women by testing first-void urine by ligase chain reaction. 7 Clin Microbiol 1994;32:2682-5.

14 Schachter J, Stamm WE, Quinn TC, et al. Ligase chain reaction to detect Chlamydia trachomatis infection of the reaction to detect Chlamydia trachomatis

15 Ånestad G, Berdal BP, Scheel O, et al. Screening urine samples by leukocyte esterase test and ligase chain reaction for ples by leukocyte esterase test and ligase chain reaction for
chlamydial infections among asymptomatic men. $f$ Clin Microbiol 1995;33:2483-4.

16 de Barbeyrac B, Rodriguez P, Dutilh B, et al. Detection of Chlamydia trachomatis by ligase chain reaction compared with polymerase chain reaction and cell culture in urogenital specimens. Genitourin Med 1995;71:382-6.

17 Jensen IP, Thorsen P, Møller BR. Sensitivity of ligase chain reaction assay of urine from pregnant women for Chlamydia trachomatis. Lancet 1997;349:329-30.

18 Sambrook J, Fritsch EF, Maniatis T. In vitro amplification of DNA by the polymerase chain reaction. Molecular cloning, 2nd ed. Cold Spring Harbour, NY: Cold Spring Harbor Laboratory Press, 1989;2:14.2-14.35. 